\title{
A “Class-A2" Ultra-Low-Loss Magnetic Ballast for T5 Fluorescent Lamps-A New Trend for Sustainable Lighting Technology
}

\author{
S. Y. (Ron) Hui, Fellow, IEEE, D. Y. Lin, Member, IEEE, W. M. Ng, and Wei Yan, Member, IEEE
}

\begin{abstract}
The high-voltage and low-current features of T5 lamps imply that the copper and core losses of the magnetic ballast can be greatly reduced. This paper shows that magnetic ballasts for high-voltage T5 lamps are not only feasible but their luminous and ballast-loss performance can be better than those of the electronic ballasts. Contrary to common belief, high frequency operation of T5 $28 \mathrm{~W}$ lamps increases the luminous efficacy by an average of $3.6 \%$ only (less than 5\%). Practical implementation of an ultralow-loss magnetic ballast system for $\mathrm{T} 528 \mathrm{~W}$ lamps is presented. Its total system power is less than the $32 \mathrm{~W}$ upper limit specified for Class A2 of energy-efficient electronic ballast for T5 28 W lamps. High-luminous efficacy of $75.63-77.66 \mathrm{~lm} / \mathrm{W}$ can be achieved. This important breakthrough has the potential of reversing the existing trend of using electronic ballasts as the energy-saving technology in lighting industry. With a better luminous efficacy, lower product and maintenance costs, much longer lifetime, and the use of recyclable metallic materials over its electronic counterparts, this patent-pending proposal provides a truly sustainable lighting solution to the lighting industry.
\end{abstract}

Index Terms-Ballasts, lighting, lighting control.

\section{INTRODUCTION}

$\mathbf{T}$ 5 FLUORESCENT lamps have been increasingly used in both office and industrial applications. Compared with T8 lamps, the T5 lamps have smaller diameters and higher luminance. Moreover, some T5 lamps have an improved phosphor coating that prevents mercury from being absorbed into the phosphor and the bulb glass. The T5 lamps can, therefore, have less impact on the global environment than the T8 lamps [1]. Unlike LED tubes, which still have the binning problems (i.e., the color temperature of LED tubes varies from one manufacturer to another and a lack of common color standard), the T5 lamps have common color temperature standard and so users do not have to worry about future color mismatch problem in lamp replacement. However, T5 lamps with small tube diameters require a higher lamp voltage to sustain the lamp current. Therefore, for power higher than $28 \mathrm{~W}$, it has been tradition-

Manuscript received January 26, 2010; revised April 21, 2010 and June 13, 2010; accepted June 29, 2010. Date of current version February 11, 2011. Recommended for publication by Associate Editor M. Ponce-Silva.

S. Y. (Ron) Hui, W.M. Ng, and W. Yan are with the Centre for Power Electronics, City University of Hong Kong, Kowloon, Hong Kong (e-mail: eeronhui@cityu.edu.hk; eewmng@cityu.edu.hk; ee114868@cityu.edu.hk).

D.Y. Lin is with the School of Physics and Information Engineering, Jianghan University, Wuhan 430056, China (e-mail: deyanlin@student.cityu.edu.hk).

Color versions of one or more of the figures in this paper are available online at http://ieeexplore.ieee.org.

Digital Object Identifier 10.1109/TPEL.2010.2058128 ally accepted in lighting industry that only electronic ballasts, which can generate a high voltage using resonant circuit, can be used to operate the T5 lamps. Electronic ballasts, limited by the short lifetime of the electrolytic capacitors, will eventually become electronic waste and, thus, resulting in long-term pollution of soil and water. Environmental study [2], [3] on the amount of PBDE, which is the flame-retardant chemical used in printed circuit boards in South China, has confirmed that both freshwater and seawater fishes in this region have high level of polybrominated diphenyl ethers (PBDE) several times higher than fishes in other countries.

THE sustainable lighting technology should satisfy the criteria of 1) energy saving; 2) long lifetime; and 3) recyclability. Recyclability inherently implies reduction of electronic waste and further mining that unavoidably cause damage to the environment. Comparisons of magnetic ballasts and electronic ballasts are reported in [4]-[6]. It should be noted that dimmable magnetic ballasts are possible [5]-[8]. This paper presents a novel T5 electromagnetic ballast that meets the three criteria for sustainable lighting technology. Contrary to a common belief that high-frequency operation of fluorescent lamps would generate $10 \%-15 \%$ more light than low-frequency operation, practical tests on 40 samples of $\mathrm{T} 528 \mathrm{~W}$ lamps indicate that only an average of $3.6 \%$ extra light arises from high-frequency operation. Experimental results have confirmed that the ultralow-loss (ULL) T5 magnetic ballast system has higher system efficiency and efficacy than their electronic counterparts for T5 lamp. Detailed experimental and simulation results are included to confirm the theory.

\section{ULL FEATURES OF MAGNETIC BALLASTS FOR T5 LAMPS}

T5 lamps were originally designed to be driven by electronic ballasts, which can use the resonant tanks to generate highignition voltage. For T5 28 and $35 \mathrm{~W}$, the ON-state lamp voltages at high-frequency operation are 167 and $209 \mathrm{~V}$, respectively. These high voltage levels are close to the mains voltage of 220 $240 \mathrm{~V}$. Traditionally, magnetic ballasts were thought to be not suitable for driving high voltage lamps such as T5 lamps. The technical challenges for developing magnetic ballasts that can outperform electronic ballasts for T5 lamps are given in the following.

1) Sufficient ignition voltage.

2) End of life detection for aged or faulty lamps.

3) Provision of high-lamp voltage to sustain the lamp arc after lamp ignition. 


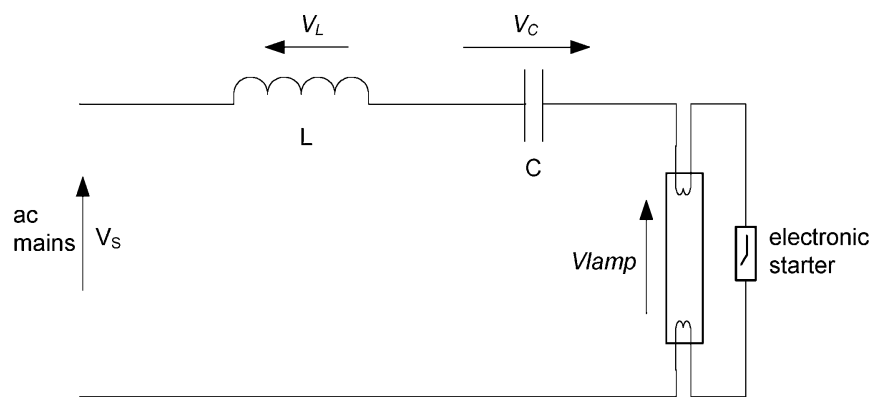

Fig. 1. Circuit diagram of the magnetic ballast ( $L C$ ballast) for $\mathrm{T} 528 \mathrm{~W}$ lamps.

TABLE I

INITIAL ASSESSMENT OF LOSS COMPONENTS

\begin{tabular}{|l|l|l|}
\hline Lamp Type & T8 36W & T5 28W \\
\hline Rated voltage $($ Vrms $)$ & 103 & 167 \\
\hline Rated current $($ Arms $)$ & 0.44 & 0.175 \\
\hline Conduction $\operatorname{loss}\left(i^{2} R\right)$ & $100 \%$ & $16 \%$ \\
\hline Core loss $(\propto$ I or $\phi$ ) & $100 \%$ & $40 \%$ \\
\hline
\end{tabular}

4) Less ballast loss than the electronic counterparts.

The requirements 1) and 2) can be met by using electronic starters [9]-[13]. Electronic starters, developed in late 1990s for T8 lamps, can be applied to the T5 lamps in general. End-oflife detection has been a common feature among some electronic starters [9], [11]. Since the T5 lamps have ON-state voltage close to the mains voltage, series inductive-capacitive $(L C)$ ballasts (see Fig. 1) previously suggested for high-voltage lamps can be used [9], [10]. As the voltage vector of the capacitor is opposite to that of an inductor, the voltage drop across the inductor can be partially or totally cancelled by the voltage vector of the capacitor. Thus, the requirement 3) can be met with an $L C$ ballast. Since only an inductor and a nonelectrolytic capacitor are used in this passive ballast, long lifetime is expected and the iron core and copper winding of the inductor can be recycled.

Since T8 $36 \mathrm{~W}$ lamps are being replaced by T5 $28 \mathrm{~W}$ lamps, it is meaningful to use them for comparison. Table I contains a comparison of typical manufacturers' data for T5 and T8 lamps. It can be seen that high-voltage T5 lamps have high ONstate voltage and low ON-state current when compared with T8 lamps of similar power. For magnetic ballasts, the power losses include the conduction and core losses. Since conduction loss is proportional to the square of the current, the low-current feature of T5 lamps enables huge reduction of the conduction loss.

In Table I, the conduction loss of a T8 magnetic ballast is used as a reference (100\%). Assuming that the winding resistance of the magnetic ballasts for T5 and T8 lamps are identical, the conduction loss of the T5 magnetic ballast is only $16 \%$ that of the T8 magnetic ballast. This is an $84 \%$ reduction in conduction loss. The core loss is proportional to the magnetic flux, which in turn is proportional to the current in the magnetic ballast. In this regard, the core loss of a $\mathrm{T} 528 \mathrm{~W}$ magnetic ballast is only $40 \%$ that of a T8 $36 \mathrm{~W}$ ballast, resulting in $60 \%$ reduction in core loss. Based on this theoretical assessment, significant reduction in both conduction and core losses can be achieved in the magnetic ballasts for T5 lamps. Therefore, it is worthwhile to practically evaluate the energy-saving potential of magnetic ballast for T5 lamps, particularly knowing that magnetic ballasts can last for tens of years and can be recycled without creating toxic and nonbiodegradable electronic waste. The information in Table I provides the ground for developing magnetic ballasts that are more efficient than electronic ones in order to meet the requirement 4).

\section{COMPUTER-Aided Design OF LC BALLAST FOR T5 $28 \mathrm{~W}$ LAMPS}

\section{A. Physical Discharge Lamp Model}

Fig. 1 shows the circuit diagram of the ballast system. It consists of an inductor (choke), a capacitor, and an electronic starter with end-of-life detection function. The steady-state circuit equation for the circuit in Fig. 1 can be expressed as

$$
V_{s}=I_{s}\left(r+j \omega L+\left(\frac{1}{j \omega C}\right)\right)+V_{\text {lamp }}
$$

where $V_{s}$ is the ac input voltage, $I_{s}$ is the input current, $r$ is the winding resistance of the inductor $L, C$ is the capacitance, and $V_{\text {lamp }}$ is the total voltage across the lamp. For T5 high-efficient lamps, the rated current is specified at $175 \mathrm{~mA}$. From (1), the lamp current equation is

$$
I_{s}=\frac{V_{s}-V_{\text {lamp }}}{(r+j \omega L+1 / j \omega C)} .
$$

Since $V_{\text {lamp }}$ is a highly nonlinear function when the lamp is operated at mains frequency, it is appropriate to use an accurate lamp model.

The design of the magnetic ballast for high-voltage lamps is based on the $L C$ ballast topology previously proposed for high-voltage fluorescent lamps [9], [10]. To precisely determine the $L C$ ballast parameters for a T5 $28 \mathrm{~W}$ lamp, the physical discharge lamp model reported in [14] and [15] is adopted for this study. This lamp model has the unique feature of including the electron density as a variable. This allows the model to predict the "turn-ON voltage spike" of the discharge lamps. For high-voltage lamps with lamp voltage close to the mains voltage such as T5 $28 \mathrm{~W}$ lamps, the presence of such voltage spike is an indication that sufficient voltage is available to sustain the lamp arc in each half cycle of the ac mains.

The lamp model equations are listed as follows:

$$
\begin{aligned}
\frac{d T_{e}}{d t} & =\frac{a_{1}\left(i^{2} R-P_{\mathrm{rad}}-P_{\mathrm{con}}\right)}{n_{e}} \\
P_{\mathrm{rad}} & =a_{2} n_{e} \exp \left(\frac{-e a_{3}}{k T_{e}}\right) \\
P_{\mathrm{con}} & =a_{4}\left(T_{e}-T_{g}\right) n_{e} \\
\frac{d n_{e}}{d t} & =n_{e}\left(v_{i}-v_{\mathrm{diff}}\right) \\
R & =\frac{l}{n_{e} e \mu_{e} s}
\end{aligned}
$$


TABLE II

PARAMETERS FOR T5 $28 \mathrm{~W}$ LAMPS

\begin{tabular}{rl|c|c|}
\hline$a l$ & $a 2$ & $a 3$ & $a 4$ \\
\hline $3.106 \mathrm{e} 22$ & $6.601 \mathrm{e}-12$ & 8.23 & $7.4 \mathrm{e}-19$ \\
\hline$a 6$ & $a 7$ & $a 8$ & $a 9$ \\
\hline 23.5 & 1.64 & $1.5 \mathrm{e} 15$ & 1.03 \\
$v_{i}$ & $=a_{5} \exp \left(\frac{-e a_{6}}{2 k T}\right)+a_{7} E$ \\
$V(t)$ & $=a_{8} L \frac{d i}{d t}+r i+R i+V_{\mathrm{ele}}$ \\
$v_{\mathrm{diff}}$ & $=\left(\frac{2.4}{R_{a}}\right)^{2} D_{a}$ \\
$\mu_{e}$ & $=\frac{6701960}{T_{e}}$ \\
$E$ & $=\frac{i}{n_{e} e \mu_{e} s}$ \\
$D_{a}$ & $=\frac{\mu_{i} k\left(T_{e}+T_{g}\right)}{e}$ \\
$\mu_{i}$ & $=a_{9} * 0.14$ \\
$T_{\mathrm{g}}$ & $=a_{10} i^{2} R+T_{0}$ \\
$d t$ & $=\frac{i}{C}$
\end{tabular}

where $T_{e}$ is the electron temperature, $i$ is the lamp current, $R$ is the lamp resistance, $P_{\text {rad }}$ is the radiation loss in the lamp, $P_{\text {con }}$ is the thermal conduction loss in the lamp, $n_{e}$ is the electron density, $k$ is the Boltzmann constant, $e$ is the charge on an electron, $v_{i}$ is the ionization frequency of every electron, $\mathrm{V}(t)$ is the power-supply voltage, $L$ is the ballast inductance, $r$ is the ballast resistance, $V_{\text {ele }}$ is the electrode voltage drop in the lamp, $v_{\text {diff }}$ is the diffusion frequency of every electron, $\mu_{e}$ is the electron mobility, $\mu_{i}$ is the ion mobility, $T_{g}$ is the gas temperature, $T_{0}$ is the lamp wall temperature, $C$ is the ballast capacitance, and $V_{c}$ is the voltage across the capacitor in the $L C$ ballast.

The parameters for the T5 $28 \mathrm{~W}$ lamp can be obtained by feeding the measured lamp voltage and current data into the model equations in an iterative manner. With the help of evolutionary algorithm such as Genetic Algorithm, the error function can be minimized so that the parameters $a_{1}-a_{10}$ of each time of lamp can be obtained. Details of this physical lamp modeling technique can be found in [14] and [15]. Based on this method, the parameters for T5 $28 \mathrm{~W}$ lamps are shown in Table II.

\section{B. Computer-Aided Studies}

To operate the T5 lamp with electromagnetic ballast, there are two possible circuit topologies: conventional inductor ballast circuit shown in Fig. 2, and an $L C$ ballast shown in Fig. 3.

1) Simulation of the Inductive Ballast Driven System: Based on the physical discharge lamp model, simulation of a T5 $28 \mathrm{~W}$ lamp using the inductor ballast has been conducted. $V_{s}=230$ $\mathrm{V}, L=1.36 \mathrm{H}$, and $r$ (the resistor of the inductor) $=49.1 \Omega$ for the circuit shown in Fig. 2. The simulation waveforms for lamp voltage, lamp current, and the source voltage are shown in

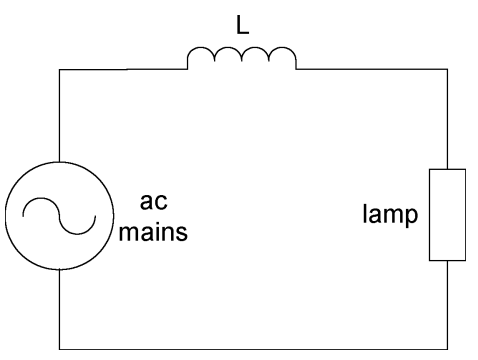

Fig. 2. Inductor-based magnetic ballast circuit.

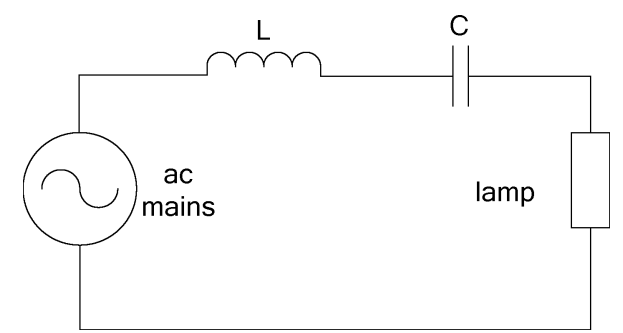

Fig. 3. Inductive-capacitive ballast.
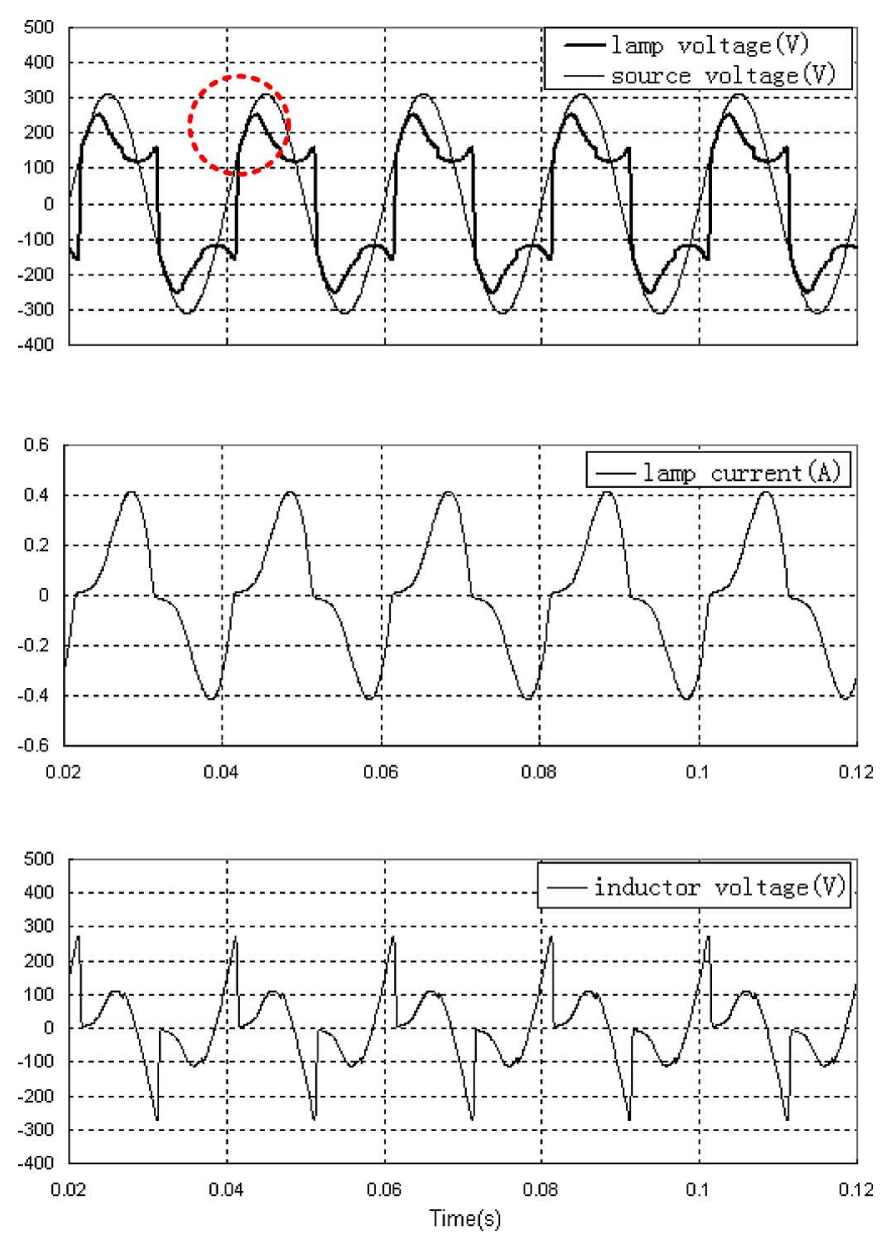

Fig. 4. Simulation results of the inductor ballast for a T5 $28 \mathrm{~W}$ lamp: (top thin curve) source voltage and (top thick curve) lamp voltage; (middle) lamp current; (bottom) inductor voltage. 
Fig. 4. It is important to note in the dotted circle that the sharp ignition voltage spike does not exist in the simulated voltage waveform of the T5 lamp. The absence of this sharp voltage spike usually means that the lamp arc cannot be sustained. This has been proven in our experiment that this magnetic ballast cannot drive the T5 $28 \mathrm{~W}$ lamp satisfactorily. The lamp arc distinguishes soon after initial ignition.

The inductor ballast is not suitable for high voltage lamps with ON-state voltage close to ac mains voltage. This circuit topology is not suitable for T5 $28 \mathrm{~W}$ lamps, which has typical ON-state lamp voltage of $167 \mathrm{~V}$ (high-frequency) and $180 \mathrm{~V}$ (mains frequency) that is close to the mains voltage of $230 \mathrm{~V}$. It is important to note that the lamp voltage is limited by the ac mains voltage. In practice, it means that the lamp may not be ignited because the voltage available to the lamp arc may not be sufficient.

2) Simulation of the LC Ballast Driven System: The $L C$ ballast driven system in Fig. 3 has been simulated with: $V_{s}=230$ $\mathrm{V}, L=3.2 \mathrm{H}, C=1.45 \mu \mathrm{F}$, and $r=49.1 \Omega$. The simulation results are included in Fig. 5. It is important to note that the high ignition voltage spike can be observed in the dotted circle of the lamp voltage waveform in each half cycle. The success of the lamp arc discharge results in a change of voltage, which is reflected in the change of inductor voltage in Fig. 5. The circuit takes the advantage of the opposite phase of the inductor and capacitor voltages. The inductor and capacitor voltages are found to be out of phase. The use of the capacitor allows the voltage drop across the inductor to be reduced so that more voltage will be available for the lamp arc. This important feature can be confirmed by both simulation and practical measurements. The physical lamp model is also used under different power levels for a T5 $28 \mathrm{~W}$ lamp so that the simulated variation of the lamp voltage and current can be obtained and compared with measurements. Fig. 6 shows the measured and simulated lamp voltage as a function of lamp current. These results are in good agreement and confirm that the physical model used in this study provides a sufficient level of accuracy.

\section{EXPERIMENTAL VERIFICATION}

\section{A. Low- and High-Frequency Operation of T5 28 W Lamps}

In order to compare the effects of low- and high-frequency operation of T5 lamps, a total of 40 samples of T5 $28 \mathrm{~W}$ lamps (20 samples of Philips Lamps: TL5 28 W/865 and 20 samples of Osram Lamps: L 28 W/865) have been tested. These new lamps are tested after the normal 100-h continuous burn-in operation. During the burn-in period, only Philips electronic ballasts are used to power the lamps at the rated power. These lamps are then tested with the 1) Philips electronics ballasts at high frequency and 2) ULL ballasts at mains frequency. The luminous flux measurements are carried out with the lamps housed inside the integrating sphere and with the use of the photo-spectrocolorimeter system calibrated with a standard lamp.

Table III shows the averaged luminous efficacy measurements of the T5 $28 \mathrm{~W}$ lamps operated at mains and high frequency based on the 40 lamp samples. The average luminous efficacy of the lamps (without considering the ballast loss) at low and high
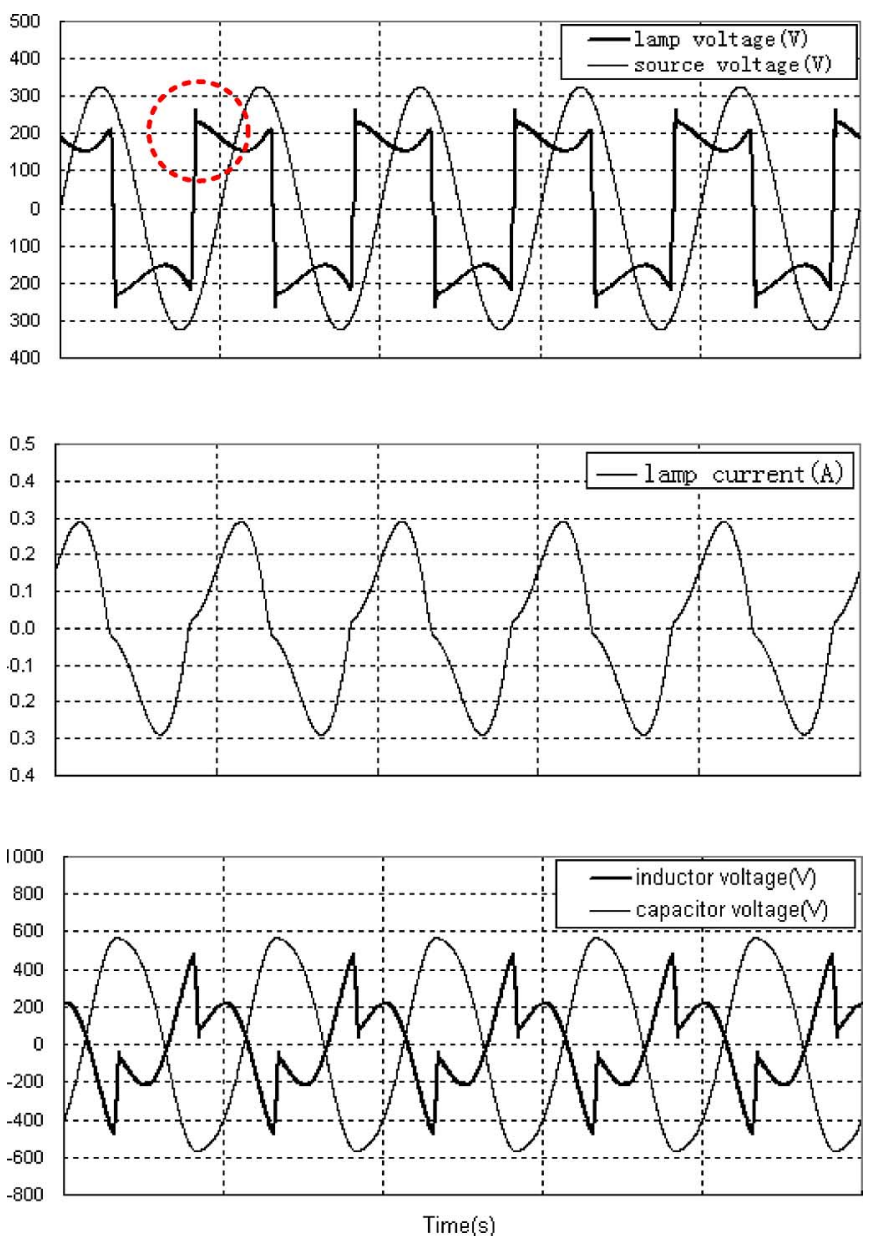

Fig. 5. Simulation results of the $L C$ ballast for a T5 $28 \mathrm{~W}$ lamp: (top thin curve) source voltage and (top thick curve) lamp voltage; (middle curve) lamp current; (bottom thin curve) capacitor voltage and (bottom thick curve) inductor voltage.

frequency are found to be 83.99 and $86.98 \mathrm{~lm} / \mathrm{W}$, respectively. Contrary to the common belief, this set of results shows that high-frequency operation of T5 $28 \mathrm{~W}$ lamps only increases the efficacy by an average of $3.55 \%$ (less than 5\%).

\section{B. Practical System Tests}

The $L C$ magnetic ballast has been applied to these $28 \mathrm{~W}$ T5 lamps that have gone through the 100-h burn-in period. Typical experimental results for full power operation at input voltage of $230 \mathrm{~V}$ are shown in Figs. 7 and 8. It is important to note from Fig. 8 that the lamp ignition voltage spike occurs at every half cycle as predicted in the simulated lamp voltage in Fig. 5. Stable lamp operation has been observed at $V_{s}=230 \mathrm{~V}$. The power factor is about 0.65 (leading). It should be noted that, in some regions, the power factor requirement for energy-efficient residential lighting fixtures has been reduced from 0.9 to 0.5 for energy-saving products [18] in the Energy Star program.

Experiments are then repeated to operate the $L C$ ballast down to $V_{s}=180 \mathrm{~V}$ in order to evaluate its performance under dimming operation. The corresponding measured waveforms are shown in Figs. 9 and 10. The power factor is about 0.84. The 


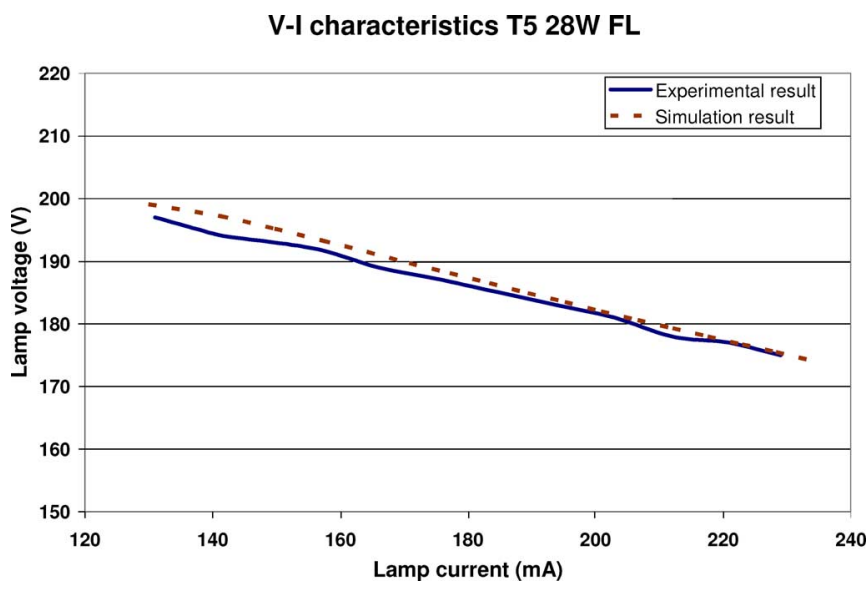

Fig. 6. Simulated and measured voltage-current characteristic of T5 $28 \mathrm{~W}$ lamp.

TABLE III

COMPARISON OF LUMINOUS EFFICACY OF T5 28 W LAMPS UNDER LOW- AND HIGH-FREQUENCY OPERATIONS

\begin{tabular}{|c|c|c|c|c|}
\hline & & $\begin{array}{l}\text { Averaged luminous } \\
\text { efficacy at Mains- } \\
\text { frequency } \\
\text { (ULL ballast) }\end{array}$ & $\begin{array}{l}\text { Averaged luminous } \\
\text { efficacy at High- } \\
\text { Frequency } \\
\text { (Philips) }\end{array}$ & $\begin{array}{c}\text { Increase in } \\
\text { efficacy }\end{array}$ \\
\hline \multirow{3}{*}{$\begin{array}{l}\text { New lamps } \\
\text { after } 100-\mathrm{h} \\
\text { burn-in }\end{array}$} & $\begin{array}{c}\text { Philips } \\
\text { (20 samples) }\end{array}$ & $84.04 \mathrm{~lm} / \mathrm{W}$ & $87.48 \mathrm{~lm} / \mathrm{W}$ & $4.09 \%$ \\
\hline & $\begin{array}{c}\text { Osram } \\
\text { (20 samples) }\end{array}$ & $83.93 \mathrm{~lm} / \mathrm{W}$ & $86.48 \mathrm{~lm} / \mathrm{W}$ & $3.04 \%$ \\
\hline & $\begin{array}{c}\text { Average } \\
\text { (40 samples) }\end{array}$ & $83.99 \mathrm{~lm} / \mathrm{W}$ & $86.98 \mathrm{~lm} / \mathrm{W}$ & $3.55 \%$ \\
\hline
\end{tabular}

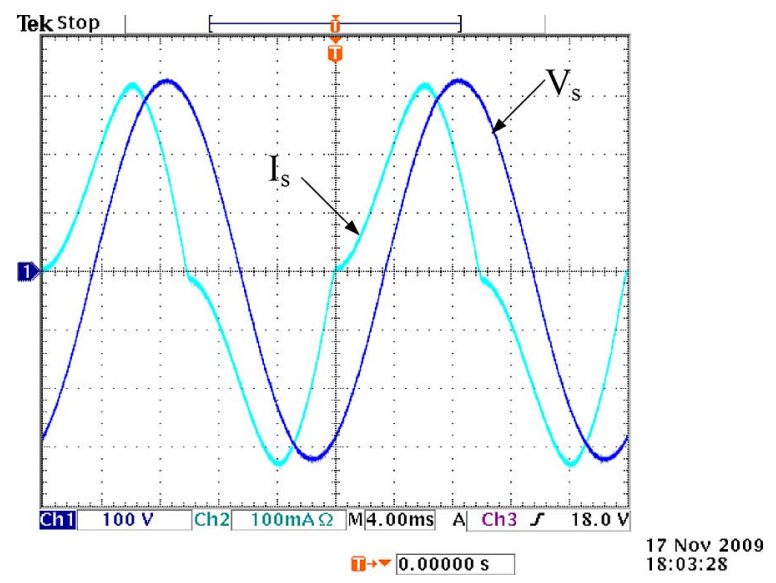

Fig. 7. Measured input voltage $V_{s}$ and input current $I_{s}$ under full-power operation at $V_{s}=230 \mathrm{~V}$ (without PFC).

lamp voltage at $180 \mathrm{~V}$ operation remains almost the same as that of the $230 \mathrm{~V}$ operation, but the lamp current is reduced at a $V_{s}$ of $180 \mathrm{~V}$. However, stable lamp operation has also been observed under this dimming condition.

In order to increase the input power factor, a parallel inductor can be added to the $L C$ ballast. With the insertion of this powerfactor-correction (PFC) inductor of $7.4 \mathrm{H}$ across the input ac votlage supply, the input voltage and current waveforms are shown in Fig. 11. The power factor is now increased to about 0.9 (leading). Comparing with Fig. 7, Fig. 11 clearly shows that the zero crossing points of the voltage and current waveforms are closer in phase after PFC is incorporated. It should be noted that

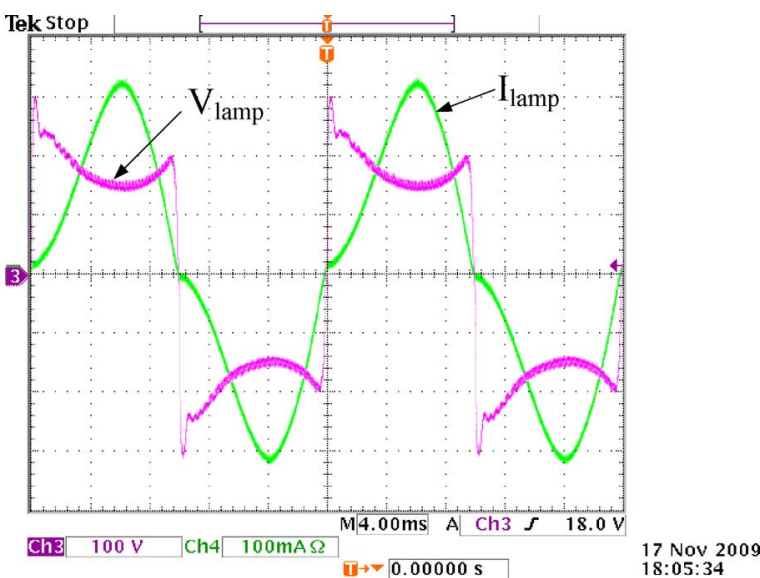

Fig. 8. Measured lamp voltage $V_{\text {lamp }}$ and lamp current $I_{\text {lamp }}$ under fullpower operation at $V_{s}=230 \mathrm{~V}$ (without PFC).

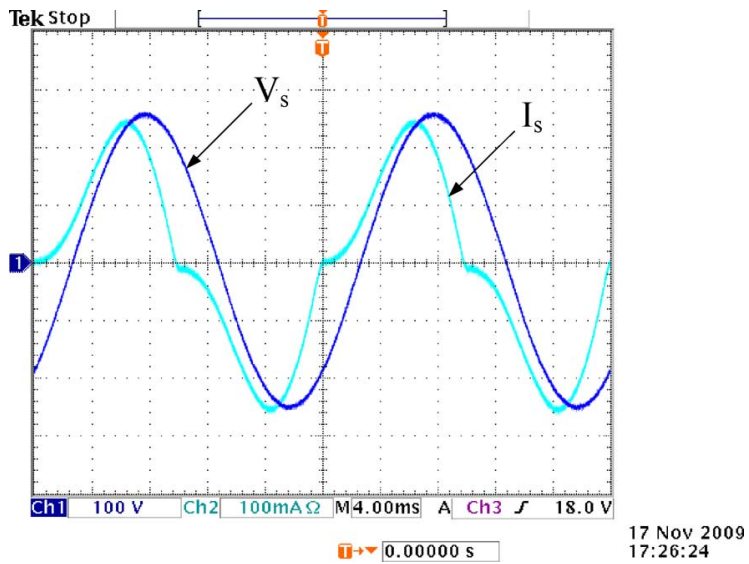

Fig. 9. Measured input voltage $V_{s}$ and input current $I_{s}$ under reduced power operation $(20 \mathrm{~W})$ at $V_{s}=180 \mathrm{~V}$ (without PFC).

this size of this inductor is not excessive because only a small current will go through this inductor and, thus, very thin winding can be used. It will be shown that only $0.8 \mathrm{~W}$ will be dissipated in this inductor. Fig. 12 shows the measured lamp voltage and current waveforms of the lamp using this $L C$ ballast with PFC. These lamp waveforms look identical to those recorded in Fig. 8 because the PFC inductor does not affect the lamp operation.

The electrical and luminous performances of the ULL $L C$ ballast (with and without PFC) have been compared with electronic ballasts commercially available in the market. Using the 40 lamp samples, 1) the $L C$ ballast with PFC inductor; 2) $L C$ ballast without PFC inductor; and 3 ) an electronic ballast are tested and compared. All tests are carried out in a photo-spectro-colorimeter with an integrating sphere. To ensure accurate measurements at both low- and high-frequency operations, the Voltech PM 6000 power analyzer is used for all power measurements. Table IV includes the average measurements obtained when the three systems are tested at $V_{s}=230 \mathrm{~V}$ using the 40 lamp samples. While the input power values of the three systems are almost the same, it is noted that the ballast loss of the $L C$ ballast $(2.5 \mathrm{~W}$ ) is much smaller than those of the electronic ballast $(4.76 \mathrm{~W})$. The use of the PFC inductor for improving the power factor to 0.9 would 
TABLE IV

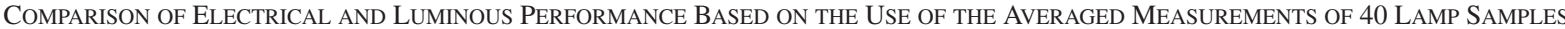

\begin{tabular}{|c|c|c|c|c|c|c|}
\hline Model & $\begin{array}{c}\text { Input } \\
\text { Power } \\
\text { (W) }\end{array}$ & $\begin{array}{c}\text { Lamp } \\
\text { Power } \\
\text { (W) }\end{array}$ & $\begin{array}{c}\text { Ballast } \\
\text { Loss } \\
\text { (W) }\end{array}$ & $\begin{array}{c}\text { Luminou } \\
\text { s Flux } \\
\text { (Lumen) }\end{array}$ & $\begin{array}{c}\text { Energy } \\
\text { Efficiency } \\
(\%)\end{array}$ & $\begin{array}{c}\text { System } \\
\text { Luminous } \\
\text { Efficacy } \\
\text { (Lumen/Watt) }\end{array}$ \\
\hline $\begin{array}{c}\text { Ultra-low-loss } \\
\text { LC ballast }\end{array}$ & 31.2 & 28.7 & 2.5 & 2423 & 92.0 & 77.66 \\
\hline $\begin{array}{c}\text { Ultra-low-loss LC } \\
\text { ballast with PFC }\end{array}$ & 32.0 & 28.7 & 3.3 & 2420 & 89.7 & 75.63 \\
\hline $\begin{array}{c}\text { Philips EB-S128 } \\
\text { TL5 230 }\end{array}$ & 31.6 & 26.9 & 4.76 & 2411 & 85.1 & 76.30 \\
\hline
\end{tabular}

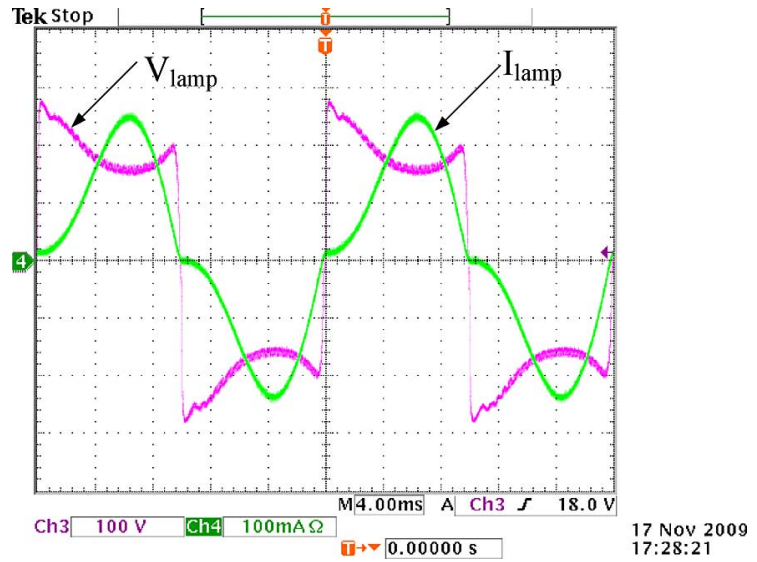

Fig. 10. Measured lamp voltage $V_{\text {lamp }}$ and lamp current $I_{\text {lamp }}$ under reduced power operation $\left(20 \mathrm{~W}\right.$ ) at $V_{s}=180 \mathrm{~V}$ (without PFC).

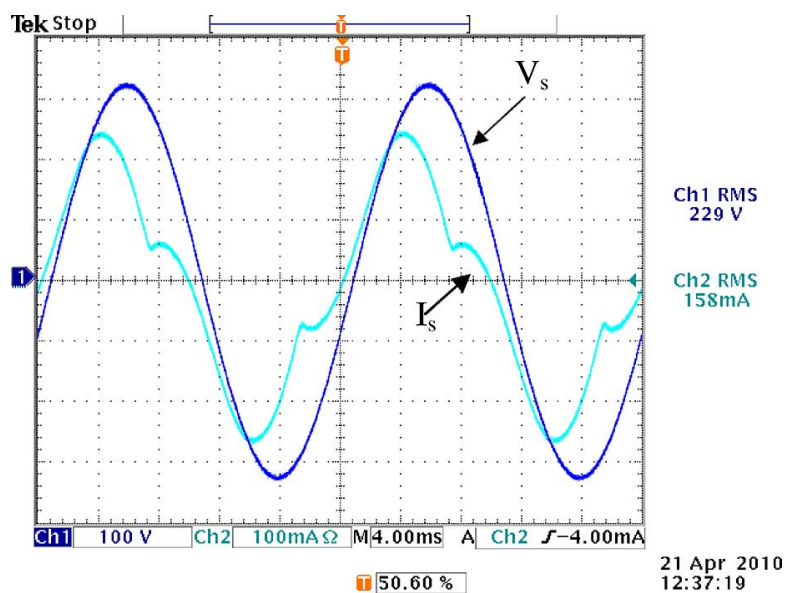

Fig. 11. Measured input voltage $V_{s}$ and input current $I_{s}$ under full-power operation at $V_{s}=230 \mathrm{~V}$ (with PFC).

increase the power consumption of the $L C$ ballast by $0.8 \mathrm{~W}$, making the total system loss $3.3 \mathrm{~W}$, which is still lower than that of the electronic ballast. The low-loss feature and, therefore, high-energy efficiency of the two versions of the $L C$ ballasts enable the $L C$ ballasts to enjoy high overall system efficacy. These practical results confirm the inherent low-loss feature of using magnetic ballast for high-voltage and low-current lamps because the "low-current" feature of the lamp enables low conduction and core losses in the magnetic choke. Consequently, the high energy efficiency $(89.7 \%-92.0 \%)$ and luminous efficacy $(75.63-77.66 \mathrm{~lm} / \mathrm{W})$ of the $L C$ ballasts are comparable if

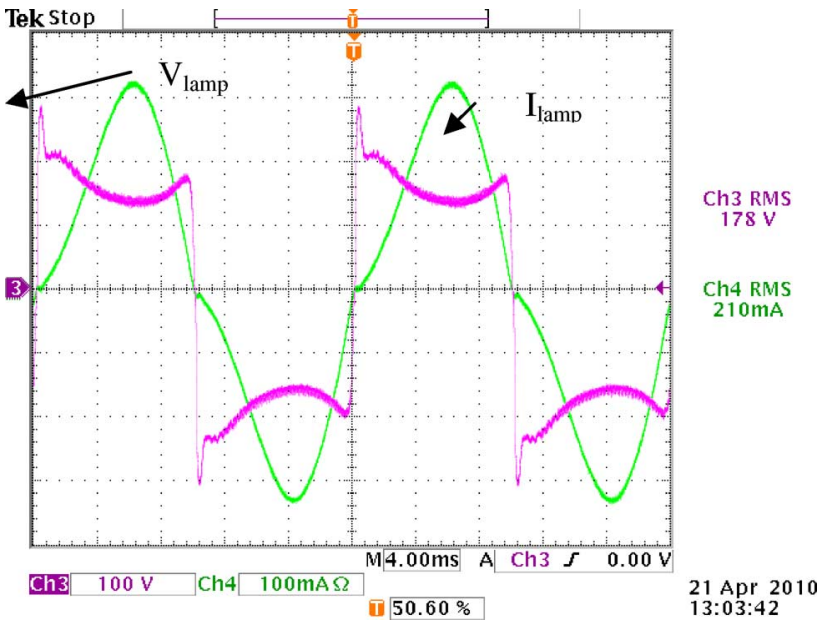

Fig. 12. Measured lamp voltage $V_{\text {lamp }}$ and lamp current $I_{\text {lamp }}$ under fullpower operation at $V_{s}=230 \mathrm{~V}$ (with PFC).

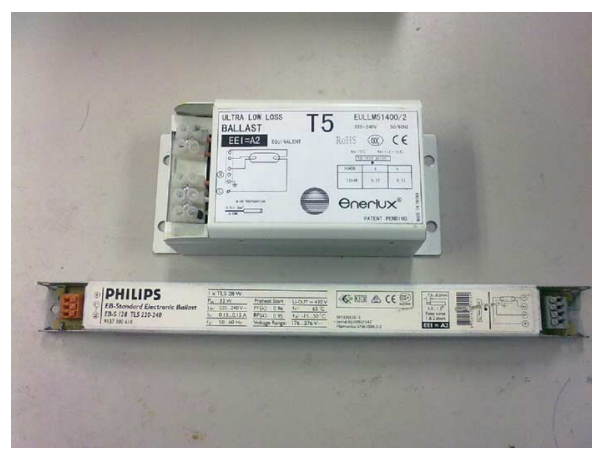

Fig. 13. (Bottom) Photograph of the electronic ballast and (top) a prototype of the $L C$ ballast.

not better than that of the electronic ballasts, despite the fact that high-frequency operation of the lamp would yield a higher luminous output of less than 5\%. A photograph of the electronic ballast and the $L C$ ballast prototype is shown in Fig. 13.

\section{CONCLUSION}

Explanations, simulation, and practical verification are provided in this paper to confirm that $L C$ ballast can match or even outperform electronic ballast in terms of energy efficiency and luminous efficacy for high-voltage and low-current lamps such as T5 $28 \mathrm{~W}$ fluorescent lamps. Based on a physical discharge lamp model, the ULL $L C$ ballast has been designed for the T5 $28 \mathrm{~W}$ fluorescent lamps. The ULL $L C$ ballast developed here 
takes advantage of the inherent low-current feature of the T5 28 W lamp, which enables a significant reduction in both conduction and core losses in the magnetic choke. In this experiment, the ULL ballast without PFC achieves an average ballast loss of $2.5 \mathrm{~W}$, a high-energy efficiency of $92.0 \%$, and a high system luminous efficacy of $77.66 \mathrm{~lm} / \mathrm{W}$. If the PFC inductor is added to increase the power factor to 0.9 , this inductor consumes a power loss of $0.8 \mathrm{~W}$ as indicated in Table IV. Consequently, the ULL ballast with PFC achieves an average ballast loss of $3.3 \mathrm{~W}$, an energy efficiency of $89.7 \%$, and an average system efficacy of $75.63 \mathrm{~lm} / \mathrm{W}$. Based on CELMA guide [17], electronic ballasts for T5 $28 \mathrm{~W}$ lamps with total power consumption not exceeding $32 \mathrm{~W}$ (i.e., ballast loss $<4 \mathrm{~W}$ ) can be classified as Class A2, which is the highest class for nondimmable electronic ballasts. (Class A1 is for dimmable electronic ballasts). Although the $L C$ ballast is not an electronic ballast, its total power consumption has met the Class A2 standard. Since inductor and nonelectrolytic capacitor are used to form the $L C$ ballast (i.e., no electronic switches, auxiliary power supply, control integrated circuits are needed), the proposal has the advantages of long lifetime, circuit simplicity, low maintenance cost, and high reliability. With the increasing electronic waste problem caused by the widespread applications of electronic ballasts, it may be time for the lighting industry and international regulatory bodies to turn to a more sustainable and environment-friendly lighting solution.

\section{ACKNOWLEDGMENT}

The authors would like to thank the Hong Kong Research Grant Council for the support of project CityU 122606. The support from the Centre for Power Electronics, City University of Hong Kong is gratefully acknowledged.

\section{REFERENCES}

[1] "T5 Fluorescent lamp system," National Lighting Information Program, Rensselaer Polytechnic Institute, Troy, NY , vol. 6, no. 1, (2002, Jul.). [Online]. Available: website http://www.lrc.rpi.edu/programs/nlpip/ publications.asp.

[2] Q. Luo, Z. W. Cai, and M. H. Wong, "Polybrominated diphenyl ethers in fish and sediment from river polluted by electronic waste," Sci. Total Environ., vol. 383, pp. 115-127, Jun. 7, 2007.

[3] C. S. C. Wong, N. S. Duzgoren-Aydin, A. Aydin, and M. H. Wong, "Evidence of excessive releases of metals from primitive e-waste processing in Guiyu, China," Environ. Pollut., vol. 148, pp. 62-72, Jan. 18, 2007.

[4] E. Persson and D. Kuusito, "A performance comparison of electronic vs. magnetic ballast for power gas-discharge UV lamps," in Proc. Rad Tech, Chicago, 1998, pp. 1-9.

[5] H. S.-H. Chung, N.-M. Ho, W. Yan, P. W. Tam, and S. Y. Hui, "Comparison of dimmable electromagnetic and electronic ballast systems-An assessment on energy efficiency and lifetime," IEEE Trans. Ind. Electron., vol. 54, no. 6, pp. 3145-3154, Dec. 2007.

[6] H.-S. Kim and T.-J. Nam, "Saving power by discharge lamps with high efficient magnetic ballast," in Proc. Int. Conf. Power Electron. Drives Energy Syst. Ind. Growth, Dec. 1-3, 1998, vol. 2, pp. 700-704.

[7] B. Szabados, "Apparatus for dimming a fluorescent lamp with a magnetic ballast," U.S. Patent 6538 395, Mar. 25, 2003.

[8] W. Yan, S. Y. R. Hui, and H. Chung, "Energy saving of large-scale highintensity-discharge lamp lighting networks using a central reactive power control system," IEEE Trans. Ind. Electron., vol. 56, no. 8, pp. 3069-3078, Aug. 2009.

[9] D. E. Rothenbuhler, S. A. Johnson, G. A. Noble, J. P. Seubert, "Preheating and starting circuit and method for a fluorescent lamp," U.S. Patent 5736 817, Apr. 7, 1998.
[10] D. E. Rothenbuhler and S. A. Johnson, "Resonant voltage multiplication, current-regulating and ignition circuit for a fluorescent lamps," U.S. Patent 5708 330, Jan. 13, 1998

[11] I.-S. Yeo, D.-H. Lee, and S.-B. Song, "A simple electronic starter capable of end-of-life protection for fluorescent lamps," in Proc. 14th Annu. Appl. Power Electron. Conf. Expo., 1999, pp. 473-479.

[12] C.-S. Liu, L.-R. Chen, N.-Y. Chu, and J.-L. Jaw, "Design of an adaptive electronic starter for fluorescent lamps," in Proc. IEEE ISIE 2005, Dubrovnik, Croatia, Jun. 20-23, pp. 423-428.

[13] L.-R. Chen, N.-Y. Chu, and C.-S. Liu, "Adaptive fluorescent lamp start control strategy for magnetic ballast system," J. Chinese Inst. Eng., vol. 31, no. 6, pp. 1089-1094, 2008.

[14] W. Yan and S. Y. R. Hui, "A semi-theoretical fluorescent lamp model for time-domain transient and steady-state simulations," IEEE Trans. Power Electron., vol. 22, no. 6, pp. 2106-2115, Nov. 2007.

[15] D. Lin, W. Yan, G. Zissis, and S. Y. R. Hui, "A simple physical low pressure discharge lamp model," in Proc. IEEE Energy Convers. Congr. Expo., 2009, pp. 2051-2058.

[16] S. Y. R. Hui, D. Y. Lin, W. M. Ng, "A passive LC ballast and method of manufacturing a passive LC ballast," Patent Application No. PCT/IB2009/007289, 03 Nov. 2009.

[17] Federation of National Manufacturers Associations for Luminaires and Electrotechnical Components for Luminaires in the European Union (CELMA) Guide for the Application of Directive 2000/55/EC on Energy Efficiency for Ballasts for Fluorescent Lighting, Annex III, no. 3.1, Jul. 2007, p. 14.

[18] Energy Efficiency Regulations (effective 2006, Nov. 15), Office of Energy Efficiency, Canada, [Online]. Available: http://oee.nrcan.gc.ca/residential/business/manufacturers/regulations/details-light-fixtures.cfm?attr $=4$.

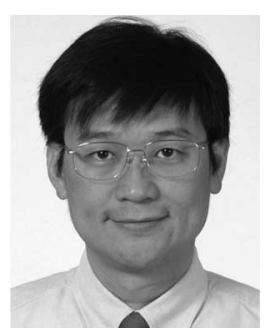

S. Y. (Ron) Hui (F'03) received the B.Sc.Eng. (Hons.) from the University of Birmingham, Birmingham, U. K., in 1984, and the D.I.C. and Ph.D. degrees from Imperial College of Science and Technology, London, U. K., in 1987.

From 1987 to 1990, he was a Lecturer at the University of Nottingham, Nottingham, U.K. In 1990, he joined the University of Technology, Sydney, N.S.W., Australia, and was appointed Senior Lecturer, in 1992, at the University of Sydney, N.S.W., where he became a Reader, in 1995. He joined the City University of Hong Kong (CityU), Kowloon, Hong Kong, as a Professor, in 1996, and was promoted to Chair Professor, in 1998. During 2001-2004, he was an Associate Dean of the Faculty of Science and Engineering at CityU. Since 2010, he has been the Chair Professorship at both CityU and Imperial College London. Heis the author or coauthor of more than 200 technical papers, including more than 140 refereed journal publications and book chapters, and about 100 conference papers, and holds more than 50 patents, which have been adopted by industry.

Dr. Hui is a Fellow of the Institution of Engineering and Technology. He has been an Associate Editor (Power Conversion) of the IEEE TRANSACTIONS ON POWER ELECTRONICS, since 1997, and an Associate Editor (Lighting Technology) of the IEEE TRANSACTIONS ON INDUSTRIAL ELECTRONICS, since 2007. He was appointed twice as an IEEE Distinguished Lecturer by the IEEE Power Electronics Society, in 2004 and 2006, respectively. He served as one of the 18 Administrative Committee members of the IEEE Power Electronics Society and was the Chairman of its Constitution and Bylaws Committee from 2002 to 2010. In 1998, he received the Excellent Teaching Award at CityU and the Earth Champion Award, in 2008. He was the recipient of an IEEE Best Paper Award from the IEEE Industry Application Society Committee on Production and Applications of Light, in 2002 and the IEEE POWER ELECTRONICS TRANSACTIONS Prize Paper Award for his publication in wireless battery charging platform technology, in 2009, and the same award in 2010 for his work in LED system theory. His inventions on wireless charging platform technology have been adopted by the Wireless Power Consortium in the new international standard "Qi" for wireless power transfer. 


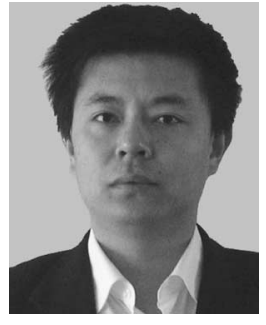

D. Y. LIN (M'09) was born in Macheng, Hubei, China, in 1972. He received the B.Sc. and M.A.Sc. degrees from the Huazhong University of Science and Technology, Wuhan, China, in 1995 and 2004, respectively, all in electrical engineering.

He was an Assistant with the Department of Electromechanical Engineering at Jianghan University, Wuhan, China, during 1995-1999, and then he became a Lecturer. Since 2008, he has been with the Department of Electronic Engineering, City University of Hong Kong, Kowloon, Hong Kong, as a Senior Research Assistant. His current research interests include modeling, control, and simulation of gas discharge lamps.

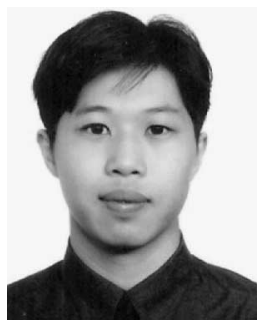

W. M. Ng received the B.Eng. degree in electronic engineering in 1998, and M.Phil. degree, in 2004, from the City University of Hong Kong, Kowloon, Hong Kong, where he is now working toward the Ph.D. degree.

From 1998 to 2000, he was an Electronic Engineer in the Astec Custom Limited. From 2000 to 2003, he was an Application Engineer in Ericsson Limited. From 2005 to 2009, he was a Senior Engineer in the City University of Hong Kong. He is a Research Fellow in Electronic Engineering, City University of Hong Kong. His current research interests include electromagnetic interference, $\mathrm{dc}-\mathrm{dc}$ converter, and lighting.

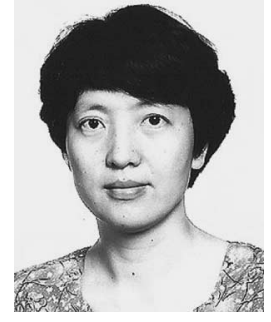

Wei Yan (M'97) received the B.Sc. and M.A.Sc. degrees from the Huazhong University of Science and Technology, Wuhan, China, in 1982 and 1988, respectively, and the Ph.D. degree from the University of Toronto, Toronto, ON, Canada, in 1996, all in electrical engineering.

She is currently a Lecturer in the Department of Electronic Engineering, City University of Hong Kong, Kowloon, Hong Kong. Her research interests include gas discharge modeling and applications, computer-aided simulation techniques, lighting science, and power electronics applications.

Dr. Yan received the Grand Applied Research Excellence Award in 2001 from the City University of Hong Kong and won the Best Paper Award from the Production and Application of Light Committee (PALC) in the IEEE IAS 2002 annual conference. 